\title{
Obscure Gastrointestinal Bleeding Caused by Small Bowel Lipoma
}

\author{
Jen-Wei Chou ${ }^{1}$, Chun-Lung Feng ${ }^{1}$, Hsueh-Chou Lai ${ }^{1}$, Chin-Chi Tsai ${ }^{1}$, Sheng-Hung Chen ${ }^{1}$, \\ Chang-Hu Hsu ${ }^{1}$, Ken-Sheng Cheng ${ }^{1}$, Cheng-Yuan Peng ${ }^{1}$ and Ping-Kuei Chung ${ }^{2}$
}

\begin{abstract}
Obscure gastrointestinal bleeding is a very rare entity which accounts for less than $5 \%$ of all gastrointestinal bleeding cases. Small bowel tumors are rare but a serious source of obscure gastrointestinal bleeding. Lipomas are the second most common benign tumors in the small bowel and can produce many complications, including gastrointestinal bleeding. Herein, we describe a case of obscure gastrointestinal bleeding caused by a small bowel tumor which was detected by capsule endoscopy and double-balloon enteroscopy preoperatively. Finally, the tumor was surgically confirmed to be a lipoma.
\end{abstract}

Key words: obscure gastrointestinal bleeding, small bowel tumor, lipoma, capsule endoscopy, double-balloon enteroscopy

(Inter Med 47: 1601-1603, 2008)

(DOI: 10.2169/internalmedicine.47.0963)

\section{Introduction}

Gastrointestinal (GI) bleeding is a common disorder; however, an unidentified source accounts for as many as $5 \%$ of all cases of GI bleeding (1). Small bowel tumors are a rare source of obscure GI bleeding (2). Lipomas are the second most common benign tumors in the small bowel and most are asymptomatic; if symptomatic, they can manifest GI bleeding, obstructive jaundice, abdominal pain, intestinal obstruction, intussusception, and even perforation (3-5). Herein, we describe a case of obscure GI bleeding caused by small bowel lipoma. The tumor was detected by capsule endoscopy (CE) and double-balloon enteroscopy (DBE) preoperatively. The patient then underwent an emergency laparotomy after the endoscopic resection failed. Finally, the microscopic examination of the resected tumor revealed it as a lipoma.

\section{Case Report}

A 57-year-old man was brought to our hospital in February 2007 because of a 5-day history of melena. He had medical history of hypertension for decades with antiplatelet therapy. In addition, he had undergone a local excision of fibrolipoma in his back 3 years prior to this presentation. He denied any history of surgery or trauma recently. On physical examination, his abdomen was soft with tenderness in the epigastric region. There were no palpable abdominal masses or rebound. The laboratory tests showed a normocytic anemia (Hb: $9.2 \mathrm{~g} / \mathrm{dL}$, normal $14-16 \mathrm{~g} / \mathrm{dL}$ ) and a positive stool occult blood (4+). The other tests were unremarkable.

An esophagogastroduodenoscopy (EGD) and a colonoscopy showed no evidence of bleeder. Small bowel barium study revealed a round filling defect in the terminal ileum (Fig. 1). CE demonstrated that it was a huge submucosal tumor in the terminal ileum (Fig. 2). Thereafter, DBE via the anus revealed an ulcerated bleeding submucosal tumor in the same location as the finding of CE (Fig. 3). The tumor was cushion sign positive and naked fat sign negative. We initially took multiple biopsies from the ulcerative surface of the tumor and the pathology of biopsy specimens showed ulcers only later. We also attempted to remove the tumor endoscopically but failed because of its large size and wide base. Then the patient was referred to our department of

${ }^{1}$ Division of Gastroenterology and Hepatology, Department of Internal Medicine, China Medical University Hospital, Taichung, Taiwan and ${ }^{2}$ Department of Surgery, China Medical University Hospital, Taichung, Taiwan

Received for publication January 29, 2008; Accepted for publication June 8, 2008

Correspondence to Dr. Hsueh-Chou Lai, t674233@ms54.hinet.net 


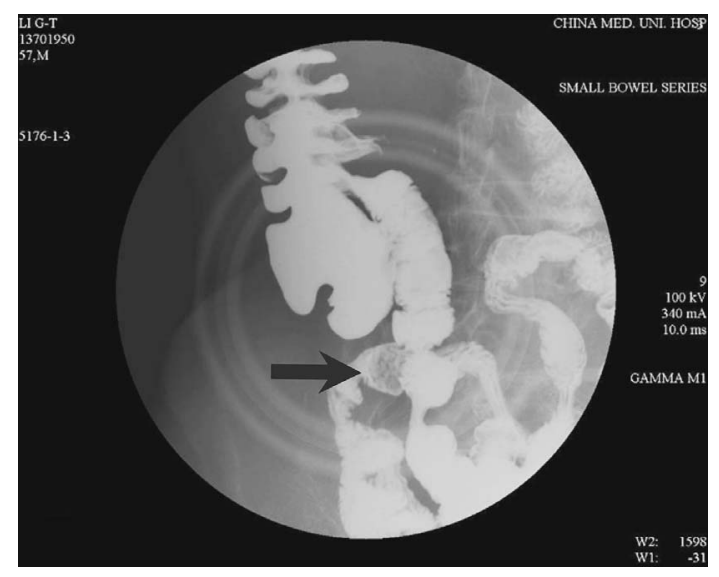

Figure 1. Small bowel barium study showing a round filling defect in the terminal ileum (arrow).

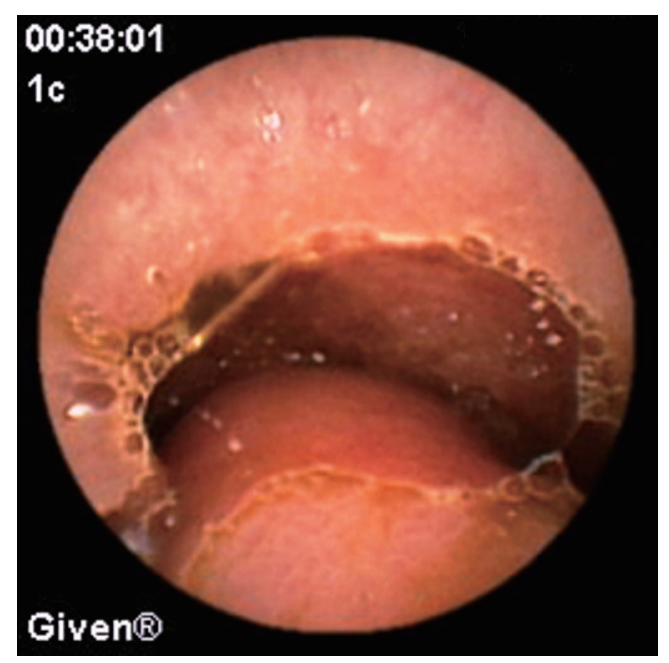

Figure 2. Capsule endoscopy showing a huge submucosal tumor in the terminal ileum.

surgery and underwent an emergency laparotomy. Laparotomy revealed a wide-based tumor, measuring $3 \times 1.5 \times 1.5 \mathrm{~cm}$ in diameter, on the mesenteric side of terminal ileum, about $25 \mathrm{~cm}$ proximal from the ileocecal valve. Segmental resection of the small bowel was performed and microscopic examination of the resected tumor showed a lipoma consisting of mature fat cells with an ulcerative surface (Fig. 4).

\section{Discussion}

Lipomas of the GI tract are benign tumors of mesenchymal origin, accounting for $5 \%$ to $6 \%$ of all GI tumors (6). They occur in the submucosa (90-95\%) and are usually single (85-90\%), mainly affecting elderly and male patients (3$6)$. The most common location of GI lipomas is the colon (65-75\%), followed by the small bowel (20-25\%); lipomas in the stomach and esophagus are rare (4). Small bowel lipomas are more common in the ileum than in the duodenum and jejunum (4). Small lipomas seldom produce symptoms, but those larger than $2 \mathrm{~cm}$ in diameter tend to be

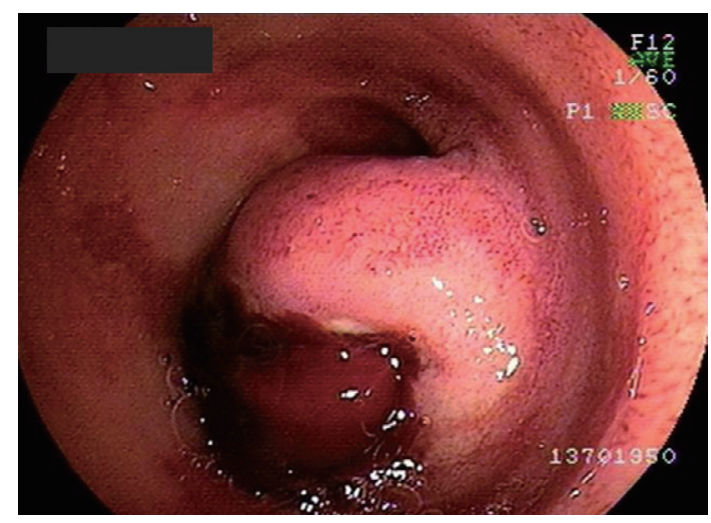

Figure 3. Double-balloon enteroscopy showing an ulcerative bleeding submucosal tumor in the terminal ileum.

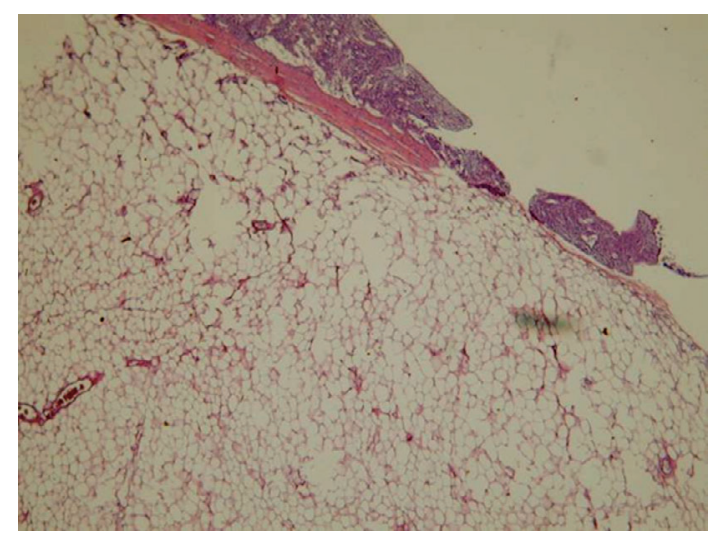

Figure 4. Microscopic examination of the resected tumor showing a lipoma consisting of mature fat cells with an ulcerative surface (Hematoxylin and Eosin staining, $\times 100$ ).

symptomatic. Symptoms include abdominal pain, GI bleeding, intestinal obstruction, intussusception, and even perforation (4).

On small bowel barium study, lipomas may appear as an ovoid, well delineated and smooth radiolucent mass (7). A "squeeze sign" has been described to diagnose lipomas where change in contour and size is seen during peristalsis and pressure on fluoroscopy (8). On abdominal computed tomography (CT), lipomas are shown as round, smooth, well-demarcated tumors with a fat attenuation coefficient of -80 to -120 Hounsfield units (9). In the present patient, we did not perform a CT due to the urgency of GI bleeding. Endoscopically, lipomas are characteristically smooth, yellowish, round or hemispherical tumors with either a pedunculated or wide base. Additionally, the "cushion sign" and "naked fat sign" are specific endoscopic characters $(10,11)$. Small bowel lipomas are difficult to diagnose by conventional EGD or colonoscopy because of deep location, anatomical tortuosity, and endoscopic inaccessibility. Despite that push endoscopy was developed two decades ago, it could not visualize the entire small bowel (12). Newly developed diagnostic modalities such as CE and DBE have increased the diagnostic yield of small bowel tumors $(13,14)$. 
Although CE can visualize the entire small bowel, this new technique has its limitations, including contraindications, difficulties in identifying the location of abnormal findings, and lack of capability of tissue sampling as well as therapeutic properties. In contrast, DBE possesses the therapeutic advantage than $\mathrm{CE}$.

The treatment of small bowel lipomas is usually dependent on its clinical manifestation and size. It is not clear whether asymptomatic small lipomas require any intervention, but conservative treatment is often indicated (15). Surgery is the mainstay therapy for most symptomatic patients, including explorative laparotomy and laparoscopic-assisted resection $(16,17)$. Endoscopic resection using an electrosurgical snare may be an alternative technique in treating lipomas if an endoscopic approach is possible (18). If a small lipoma $(<2 \mathrm{~cm})$ is pedunculated, it can be removed endoscopically by using polypectomy; if it has wide base, subtotal resection of the tumor has been reported to be effective (19). In the present patient, the findings of the large size and wide base of the tumor facilitated the choice of surgical resection after failure of endoscopic resection. Despite the failure of endoscopic therapy, it did provide the precise source and location of GI bleeding and allowed the surgeon to perform the minimum procedure necessary.

In conclusion, small bowel lipomas are rare causes of obscure GI bleeding. CE and DBE are good modalities for diagnosing small bowel lipomas. Surgical resection is needed in most symptomatic lipomas, but endoscopic treatment may be an alternative procedure if an endoscope can reach the site of lipomas.

\section{References}

1. Mujica VR, Barkin JS. Occult gastrointestinal bleeding. General overview and approach. Gastrointest Endosc Clin N Am 6: 833845, 1996.

2. Lewis BS, Kornbluth A, Waye JD. Small bowel tumours: yield of enteroscopy. Gut 32: 763-765, 1991.

3. Botsford TW, Crowe P, Crocker DW. Tumors of the small intestine. A review of experience with 115 cases including a report of a rare case of malignant hemangio-endothelioma. Am J Surg 103: 358-365, 1962.

4. Wilson JM, Melvin DB, Gray G, Thorbjarnarson B. Benign small bowel tumor. Ann Surg 181: 247-250, 1975.

5. River L, Silverstein J, Tope JW. Benign neoplasms of the small intestine; a critical comprehensive review with reports of 20 new cases. Surg Gynecol Obstet 102: 1-38, 1956.

6. Hurwitz MM, Redleaf PD, Williams HJ, Edwards JE. Lipoma of the gastrointestinal tract. An analysis of seventy-two tumors. Am J Roentgenol Radium Ther Nucl Med 99: 84-89, 1967.

7. Taylor AJ, Stewart ET, Dodds WJ. Gastrointestinal lipomas: a radiological and pathological review. AJR Am J Roentgenol 55: 1205-1210, 1990.

8. Haller JD, Roberts TW. Lipomas of the colon: a clinicopathological study twenty cases. Surgery 55: 773-781, 1964.

9. Heiken JP, Forde KA, Gold RP. Computed tomography as a definitive method for diagnosing gastrointestinal lipomas. Radiology 142: 409-414, 1982.

10. De Beer RA, Shinya H. Colonic lipomas. An endoscopic analysis
Gastrointest Endosc 22: 90-91, 1975.

11. Messer J, Waye JD. The diagnosis of colonic lipomas--the naked fat sign. Gastrointest Endosc 28: 186-188, 1982.

12. Landi B, Tkoub M, Gaudric M, et al. Diagnostic yield of pushtype enteroscopy in relation to indication. Gut 42: 421-425, 1998.

13. Schwartz GD, Barkin JS. Small bowel tumors detected by wireless capsule endoscopy. Dig Dis Sci 52: 1026-1030, 2007.

14. Yamamoto $H$, Sekine $Y$, Sato $Y$, et al. Total enteroscopy with a nonsurgical steerable double-balloon method. Gastrointest Endosc 53: 216-220, 2001.

15. Alberti D, Grazioli L, Orizio P, et al. Asymptomatic giant gastric lipoma: what to do? Am J Gastroenterol 94: 3634-3637, 1999.

16. Catena F, Ansaloni L, Gazzotti F, et al. Small bowel tumors in emergency surgery: specificity of clinical presentation. ANZ J Surg 75: 997-999, 2005.

17. Tsushimi T, Matsui N, Kurazumi H, et al. Laparoscopic resection of an ileal lipoma: Report of a case. Surg Today 36: 1007-1011, 2006.

18. Tamura S, Yokoyama Y, Morita T, Tadokoro T, Higashidani Y, Onishi S. "Giant" colon lipoma: what kind of findings are necessary for the indication of endoscopic resection? Am J Gastroenterol 96: 1944-1946, 2001.

19. Yu HG, Ding YM, Tan S, Luo HS, Yu JP. A safe and efficient strategy for endoscopic resection of large, gastrointestinal lipoma. Surgical Endoscopy 21: 265-269, 2007.

(C) 2008 The Japanese Society of Internal Medicine http://www.naika.or.jp/imindex.html 